\title{
Parathyroidectomy Versus Cinacalcet for the Treatment of Secondary Hyperparathyroidism in Hemodialysis Patients
}

\author{
Luis Alvarado $^{1} \cdot$ Nishtha Sharma $^{1} \cdot$ Roxann Lerma $^{1} \cdot$ Alok Dwivedi $^{1} \cdot$ Adeel Ahmad $^{1}$ • \\ Aimee Hechanova $^{1} \cdot$ Fernanda Payan-Schober $^{1} \cdot$ Azikiwe Nwosu $^{1} \cdot$ Eyas Alkhalili $^{1}$
}

Accepted: 26 December 2021 / Published online: 12 January 2022

(C) The Author(s) 2022

\begin{abstract}
Background Secondary hyperparathyroidism in patients with end stage renal disease on dialysis is associated with bone pain and fractures in addition to cardiovascular morbidity. Cinacalcet is the most commonly used drug to treat such patients, but it has never been compared to surgery. The goal of this study is to compare the long-term outcomes and survival between cinacalcet and parathyroidectomy in the treatment of secondary hyperparathyroidism in hemodialysis patients.

Methods Adult patients on hemodialysis who were treated with cinacalcet or parathyroidectomy in the United States Renal Data System were included. Patients treated with surgery $(n=2023)$ were compared using 1:1 propensity score matching ratio to a cohort of patients treated with cinacalcet. A Cox regression analysis was conducted to compare the overall mortality.

Results The propensity score matching successfully created two groups with similar demographics. Patients in the surgery group had a higher mean peak PTH level prior to therapy (2066.8 vs $1425.4, P<0.001)$. No difference was observed in the development of new-onset coronary artery disease $(7.7 \%$ vs $7.9 \%, P=0.8)$ or cerebrovascular disease $(7 \%$ vs $6.7 \%, P=0.8)$. Surgical patients had a higher rate of pathologic fractures $(27.8 \%$ vs $24.9 \%$, $P=0.04)$. Survival analysis showed that patients undergoing surgery had a better 5-year survival $(65.6 \%$ vs $57.8 \%)$ and were less likely to die within the study period (HR 0.77 , 95\% CI $0.7-0.85, P<0.0001$ ).

Conclusions Patients on dialysis undergoing parathyroidectomy for the treatment of secondary hyperparathyroidism have a better overall survival than those treated with cinacalcet.
\end{abstract}

\begin{abstract}
Abbreviations
ESRD End-stage renal disease

PTH Parathyroid hormone
\end{abstract}

Meeting information: Abstract was presented at the American Association of Endocrine Surgeons meeting 2021.

Eyas Alkhalili

eyas.alkhalili@ttuhsc.edu

1 Texas Tech Health Sciences Center El Paso, 2000B Woodrow Bean Transmountain Rd., B323, El Paso, TX 79911, USA
KDIGO The Kidney Disease: Improving Global Outcomes

BMD Body mass density

USRDS The United States Renal Data System

BMI Body mass index

COPD Chronic obstructive pulmonary disease

HR Hazard ratio

RR Relative risk

CI Confidence interval 


\section{Background}

Secondary hyperparathyroidism in patients with end stage renal disease (ESRD) on dialysis is associated with bone pain and fractures in addition to accelerated vascular calcification. It has been shown that elevated levels of phosphorus, parathyroid hormone (PTH), calcium, alkaline phosphatase, and fibroblast growth factor 23 are associated with cardiovascular morbidity and mortality [1-4].

Cinacalcet (Sensipar/Mimpara, Amgen) is a calcimimetic that activates the calcium-sensing receptor (CSR) on the parathyrocytes that is approved for the treatment of secondary hyperparathyroidism after showing effectiveness in reducing the levels of PTH levels as well as calcium and phosphorus levels in randomized controlled trials $[5,6]$. The Evaluation of Cinacalcet Therapy to Lower Cardiovascular Events (EVOLVE) trial, however, showed that Cinacalcet did not reduce the risk of death or major cardiovascular morbidity in patients with secondary hyperparathyroidism who are undergoing dialysis [7].

The Kidney Disease: Improving Global Outcomes (KDIGO) CKD-MBD Update Work Group recommends calcimimetics such as Cinacalcet, Calcitriol, Vitamin D analogs, or a combination of calcimimetics with calcitriol or vitamin D analogs in patients requiring PTH-lowering therapy. The guidelines also recommend parathyroidectomy in patients with severe hyperparathyroidism who fail to respond to medical therapy [4].

Parathyroidectomy for secondary hyperparathyroidism in patients with ESRD has been shown to have a higher complication and death rate compared to parathyroidectomy when performed for other indications [8]. As such, surgery has been reserved for patients with refractory disease that is otherwise uncontrolled with medical therapy. There has been a single prospective randomized study comparing parathyroidectomy with Cinacalcet in treating hyperparathyroidism, but it was performed in patients with persistent hyperparathyroidism after kidney transplantation (tertiary hyperparathyroidism). The study showed that parathyroidectomy was superior to Cinacalcet in achieving normocalcemia and improving bone mass density (BMD) [9].

The aim of this study is to compare the long-term outcomes and survival between Cinacalcet and parathyroidectomy in patients with secondary hyperparathyroidism receiving hemodialysis using The United States Renal Data System (USRDS)
Methods

\section{Data source and study population}

The USRDS is a national registry of ESRD patients which includes data from hundreds of participating hospitals across the US. www.usrds.org. The following Standard Analysis Files (SAF) from the USRDS data were used and merged to conduct the analysis: Core, Hospital, CROWNWeb clinical data, Institutional Claims, Medicare Claims, Physician/Supplier claims, and Part D.

We included patients on hemodialysis aged $\geq 18$ years treated between January 1, 2012, and December 31, 2014, with a PTH level $\geq 1000 \mathrm{pg} / \mathrm{mL}$. The study population was divided into two groups. The surgery group was identified using the current procedural terminology (CPT) for parathyroidectomy (60500), while the second group included patients who were treated with Cinacalcet during the study time-frame.

\section{Patients characteristics}

Patients' demographics and clinical characteristics were compared including age, sex, race, body mass index (BMI), and comorbid conditions. These were defined using ICD-9 and ICD-10 codes. We also included laboratory values such as albumin, hemoglobin, calcium, phosphorus, and PTH levels.

\section{Defining outcomes}

The outcomes of interest were death during the study period, overall survival, hospitalizations after initiating treatment (surgery or medical) that are related to cardiovascular or bone disease, and any procedures or surgeries performed to treat those conditions.

\section{Statistical analysis}

Due to the inequality in clinical variables between the two groups, a propensity match score was conducted. The group treated with surgery $(\mathrm{S})$ was compared using 1:1 propensity score matching ratio to a cohort of patients treated with Cinacalcet $(\mathrm{C})$. The groups were matched for age, sex, race, preoperative albumin, and hemoglobin levels, existing comorbidities (including diabetes, COPD, and cancer), and receiving a kidney transplant.

Qualitative variables were reported using frequencies and percentages, while quantitative variables were reported using means and standard deviations. The association between the variables was analyzed using an unpaired $t$ test, Chi-square test, and Fisher's exact test. A relative risk 
regression was conducted to assess the differences between the treatment groups.

A Cox regression analysis was also conducted to compare the overall mortality after surgery or medication. A Kaplan-Meier Curve was generated to show the overall probability of death after receiving either treatment. Hazard ratio (HR), 95\% confidence interval (C.I.), and $P$ values were used to describe the models. $P$ values were considered statistically significant when $<0.05$. All data analysis and management was conducted using Stata 15 (StataCorp. 2017 LLC, College Station, TX, USA) and SAS Version 9 (SAS Institute Inc., Cary, NC, USA).

\section{Results}

There were 2023 patients in each group. The propensity score matching successfully created two groups with similar demographics (Table 1). Patients in the surgery group had a higher mean peak PTH level prior to therapy ( $\mathrm{S}$ 2066.8 vs $\mathrm{C} 1425.4 \mathrm{pg} / \mathrm{mL}, P<0.001)$. The 30 -day postoperative mortality in the surgery group was $3.7 \%$. The post-intervention nadir PTH was lower in the surgery group (S 67.8 vs $516.3 \mathrm{pg} / \mathrm{mL}, P<0.001$ ). Seventeen percent of patients who underwent surgery received treatment with Cinacalcet during the study period indicating surgical failure or disease recurrence.

No difference was observed in the development of newonset coronary artery disease (S 7.7\% vs C 7.9\%, $P=0.8$ ) or cerebrovascular disease (S $7 \%$ vs C $6.7 \%, P=0.8$ ). Surgical patients had a higher rate of calcific uremic arteriolopathy (calciphylaxis) (S $2.3 \%$ vs C $1.1 \%, P=0.007$ ) and higher rate of pathologic fractures (S $27.8 \%$ vs $\mathrm{C}$ $24.9 \%, P=0.035$ ) (Table 2).

Survival analysis showed that patients undergoing surgery had a better 5-year survival (S $65.7 \%$ vs C $57.9 \%$, $P<0.0001$ ) (Fig. 1). Cox regression mortality analysis showed that patients in the surgical group were less likely to die within the study period (HR 0.77 , 95\% CI $0.7-0.85$, $P<0.0001)$. When we performed Cox regression analysis with PTH included and excluded from the propensity matching, PTH appeared to have no significant effect on the model and it resulted in similar findings (Table 3).

Table 1 Demographic variables

\begin{tabular}{|c|c|c|c|}
\hline & $\begin{array}{l}\text { Cinacalcet } \\
N=2023\end{array}$ & $\begin{array}{l}\text { Parathyroidectomy } \\
N=2023\end{array}$ & $P$ value \\
\hline Age at time of treatment, mean (SD) & $49.0(13.8)$ & $49.5(13.0)$ & 0.21 \\
\hline BMI, mean (SD) & $31.4(9.1)$ & $31.4(8.7)$ & 0.96 \\
\hline Race & & & 0.30 \\
\hline White & $741(36.6 \%)$ & $781(38.6 \%)$ & \\
\hline Black & $1192(58.9 \%)$ & $1145(56.6 \%)$ & \\
\hline Native American & $19(0.9 \%)$ & $21(1.0 \%)$ & \\
\hline Asian & $36(1.8 \%)$ & $30(1.5 \%)$ & \\
\hline Pacific Islander & $19(0.9 \%)$ & $16(0.8 \%)$ & \\
\hline Other & $14(0.7 \%)$ & $25(1.2 \%)$ & \\
\hline Don't know & $2(0.1 \%)$ & $5(0.2 \%)$ & \\
\hline Sex & & & 0.71 \\
\hline Female & $979(48.4 \%)$ & $992(49.0 \%)$ & \\
\hline Male & $1044(51.6 \%)$ & $1031(51.0 \%)$ & \\
\hline Albumin (g/dL), median (IQR) & $4.0(3.8,4.2)$ & $4.0(3.8,4.2)$ & 0.72 \\
\hline Hemoglobin (g/dL), mean (SD) & $10.5(2.1)$ & $10.5(2.2)$ & 0.78 \\
\hline Calcium corrected $(\mathrm{md} / \mathrm{dL})$, mean $(\mathrm{SD})$ & $9.2(0.8)$ & $9.2(0.9)$ & 0.095 \\
\hline Phosphorus (mg/dL), mean (SD) & $6.5(1.9)$ & $6.7(2.0)$ & $<0.001$ \\
\hline Peak PTH (pg/dL), median (IQR) & $1425.4(1174.3,1865.7)$ & $2066.8(1485.2,2965.3)$ & $<0.001$ \\
\hline Nadir PTH (pg/dL) after treatment, median (IQR) & $516.3(240.5,1020.9)$ & $67.8(12.4,250.1)$ & $<.0001$ \\
\hline Diabetes & $475(23.5 \%)$ & $481(23.8 \%)$ & 0.85 \\
\hline Kidney transplant & $673(33.3 \%)$ & $677(33.5 \%)$ & 0.92 \\
\hline COPD & $45(2.2 \%)$ & $47(2.3 \%)$ & 0.92 \\
\hline Malignant neoplasm, cancer & $38(1.9 \%)$ & $37(1.8 \%)$ & 1.00 \\
\hline Alcohol dependence & $22(1.1 \%)$ & $22(1.1 \%)$ & 1.00 \\
\hline
\end{tabular}


Table 2 Clinical outcomes

\begin{tabular}{|c|c|c|c|}
\hline & $\begin{array}{l}\text { Cinacalcet } \\
N=2023\end{array}$ & $\begin{array}{l}\text { Parathyroidectomy } \\
N=2023\end{array}$ & $P$ value \\
\hline Osteoporosis & $59(2.9 \%)$ & $55(2.7 \%)$ & 0.78 \\
\hline Pathologic fractures & $503(24.9 \%)$ & $563(27.8 \%)$ & 0.04 \\
\hline Calciphylaxis & $23(1.1 \%)$ & $46(2.3 \%)$ & 0.007 \\
\hline Skin/soft tissue debridement & $141(7.0 \%)$ & $135(6.7 \%)$ & 0.76 \\
\hline Coronary artery disease & $156(7.7 \%)$ & $158(7.8 \%)$ & 0.95 \\
\hline Cerebrovascular disease & $136(6.7 \%)$ & $141(7.0 \%)$ & 0.8 \\
\hline Peripheral vascular disease & $261(12.9 \%)$ & $255(12.6 \%)$ & 0.81 \\
\hline Cardiac dysrhythmia & $4(0.2 \%)$ & $7(0.4 \%)$ & 0.55 \\
\hline Pericarditis & $2(0.1 \%)$ & $2(0.1 \%)$ & 1.00 \\
\hline Congestive heart failure & $324(16.0 \%)$ & $310(15.3 \%)$ & 0.57 \\
\hline Death within study period & $856(42.3 \%)$ & $725(35.8 \%)$ & $<0.001$ \\
\hline Median survival in months, median (IQR) & $18(9.2,35.9)$ & $28(13.7,42.4)$ & $<0.001$ \\
\hline Cause of death & & & 0.049 \\
\hline Coronary artery disease & $32(4.1 \%)$ & $31(4.7 \%)$ & \\
\hline Cerebrovascular disease & $16(2.0 \%)$ & $24(3.6 \%)$ & \\
\hline Sepsis & $86(11.0 \%)$ & $66(10.0 \%)$ & \\
\hline Bleeding/cancer/other & $118(15.0 \%)$ & $121(18.3 \%)$ & \\
\hline Uremia & $51(6.5 \%)$ & $57(8.6 \%)$ & \\
\hline Undocumented & $482(61.4 \%)$ & $362(54.8 \%)$ & \\
\hline
\end{tabular}

$I Q R$ interquartile range

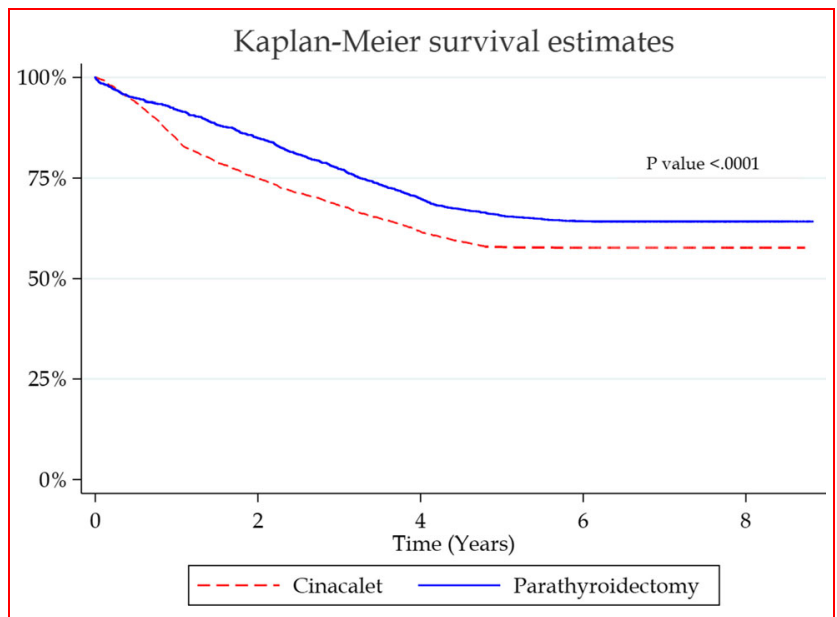

Fig. 1 Kaplan-Meier survival curve comparing treatment groups in years (parathyroidectomy: solid blue; cinacalcet: dashed red)

The cause of death was not known or recorded simply as "cardiac arrest" in 57\% of patients and as such we were not able to conduct a meaningful analysis comparing the cause of death in each group.

Multivariable hazards regression analysis showed that patients in the surgical group were more likely to develop pathologic fractures (HR 1.12, 95\% CI 1.01-1.24,
$P=0.03$ ), but no difference in the development of cardiovascular disease was observed (Table 4). We performed a sub-group analysis on the patients who underwent kidney transplant. There was no difference in the rate of pathologic fractures, but patients who underwent surgery had a lower risk of soft-tissue debridement and congestive heart failure (Table 5). Surgical patients who underwent transplant were like likely to die than those were treated with cinacalcet and underwent transplant (HR 0.47, 95\% CI 0.396-0.564, $P<0.0001$ ) (Table 6).

\section{Discussion}

In this large database study, we showed that hemodialysis patients with severe secondary hyperparathyroidism have better survival when treated by parathyroidectomy than those treated with Cinacalcet despite having more severe disease. To our knowledge, this is the first study to compare the outcomes between these treatment modalities.

The rate of parathyroidectomy to treat secondary hyperparathyroidism has decreased in recent years, mostly due to the expansion of medical therapeutic options to treat the disease $[10,11]$. Surgery is associated with a low risk of recurrent disease, improved quality of life, lower risk of tertiary hyperparathyroidism, and decreased risk of graft 
Table 3 Cox regression analysis models including and excluding PTH from the propensity matching

\begin{tabular}{llcl}
\hline & \multicolumn{2}{l}{ Restricted time $\leq 6.2$ years } \\
\cline { 2 - 4 } & HR & $95 \%$ CI & $P$ value \\
\hline $\begin{array}{l}\text { Model 1 } \\
\text { Parathyroidectomy } \\
\text { (Ref: Cinacalcet) }\end{array}$ & 0.563 & $0.51,0.63$ & $<.0001$ \\
$\begin{array}{l}\text { Model 2 } \\
\text { Parathyroidectomy }\end{array}$ & 0.58 & $0.52,0.64$ & $<.0001$ \\
$\begin{array}{l}\text { Ref: Cinacalcet) } \\
\text { Model 3 }\end{array}$ & & & \\
$\begin{array}{l}\text { Parathyroidectomy } \\
\text { Ref: Cinacalcet) }\end{array}$ & 0.55 & $0.49,0.61$ & $<.0001$ \\
\hline
\end{tabular}

Model 1: PTH serum was included in the propensity matching

Model 2: PTH serum was excluded from the propensity matching

Model 3: PTH serum was excluded from the propensity matching and adjusted for within the cox regression

Table 4 Cox proportional hazards model analysis (Ref: Cinacalcet)

\begin{tabular}{lllll}
\hline Outcome & HR & $95 \%$ CI & & $P$ value \\
\hline Pathologic fractures & 1.12 & 1.01 & 1.24 & 0.03 \\
Congestive heart failure & 0.95 & 0.83 & 1.10 & 0.55 \\
Coronary artery disease & 1.01 & 0.82 & 1.25 & 0.91 \\
Cerebrovascular disease & 1.03 & 0.83 & 1.30 & 0.76 \\
Peripheral vascular disease & 0.97 & 0.83 & 1.15 & 0.77 \\
\hline
\end{tabular}

$H R$ hazard ratio

Table 5 Relative risk model analysis of outcomes in the subgroup of patients who underwent kidney transplant (Ref: Cinacalcet)

\begin{tabular}{lllll}
\hline Outcome & RR & \multicolumn{2}{l}{$95 \%$ CI } & $P$ value \\
\hline Skin/soft tissue debridement & 0.64 & 0.42 & 0.98 & 0.041 \\
PAD & 0.83 & 0.62 & 1.11 & 0.207 \\
Congestive heart failure & 0.77 & 0.61 & 0.97 & 0.032 \\
Atherosclerotic heart disease & 0.78 & 0.53 & 1.17 & 0.244 \\
Coronary artery disease & 0.82 & 0.57 & 1.17 & 0.287 \\
Cerebrovascular disease & 0.58 & 0.32 & 1.04 & 0.069 \\
Peripheral vascular disease & 0.73 & 0.44 & 1.2 & 0.217 \\
Any cardiovascular intervention & 0.97 & 0.74 & 1.26 & 0.817 \\
Pathologic fractures & 1.03 & 0.91 & 1.16 & 0.613 \\
\hline
\end{tabular}

$R R$ relative risk

failure in transplant recipients [12-15]. In 2004, Kestenbaum et al. have reported improved survival following parathyroidectomy in patients with secondary hyperparathyroidism when compared to those who did not undergo surgery [16]. Our study shows that the survival advantage of surgery over medical therapy persists more than a decade later and surpasses that of Cinacalcet. Parathyroidectomy in ESRD patients, however, is associated with significant perioperative risks including a twopercent 30-day postoperative mortality reported in the literature and $3.7 \%$ mortality risk in our study [8]. Due to these risks, clinicians follow the KDIGO guidelines and only refer patients with severe refractory disease for surgery [4].

While Cinacalcet has been shown to lower PTH levels and improve calcium-phosphorus homeostasis, it failed to reduce the risk of death or major cardiovascular events as shown in the EVOLVE trial [6, 7]. After the EVOLVE trial showed that Cinacalcet decreased the rate of parathyroidectomy, the rate of parathyroidectomies in the USA decreased between 2004 and 2005 with Cinacalcet made available; however, the rate of surgery rose again shortly after. The suggested rationale is that the severity of the side effects caused the doses used in clinical practice to be much lower than those used in the trial [17]. The other drawback to Cinacalcet use is the high cost [18].

Despite these drawbacks, Cinacalcet remains a reasonable treatment option for secondary hyperparathyroidism. It is important to point out that all the studies thus far have compared Cinacalcet to other medical treatments but not to surgery. The only study to compare surgery to Cinacalcet was in patients with hypercalcemia in transplant recipients (Tertiary hyperparathyroidism), and it showed that surgery was superior in correcting hypercalcemia [9].

The low nadir PTH in our parathyroidectomy cohort is likely explained by aggressive resection. Other studies have shown similar findings of a suppressed nadir PTH following surgery [19]. The consequence of such surgical approach during parathyroidectomy is the over suppression of PTH and the development of adynamic bone disease which predisposes to skeletal pain and fractures (particularly when PTH levels drop below $100 \mathrm{pg} / \mathrm{mL}$ ) [20, 21]. This is a potential explanation of the slightly higher incidence of pathologic fractures in our surgical cohort. Another explanation would be the higher level of peak PTH in the surgical cohort.

Our study has a few limitations. First is its retrospective nature and the lack of randomization which made for important differences in baseline clinical characteristics between the two groups. Selection bias would mean that healthier patients are more likely to be offered surgery. We were able to create similar cohorts by the use of propensitymatch scoring to minimize the effects of these factors. The use of a large outcomes database makes it difficult to track and extract certain relevant data as was apparent in the lack of exact cause of death in most patients, making a meaningful direct cause of mortality analysis difficult to conduct. 
Table 6 Cox regression analysis with risk of death in the outcomes in the subgroup of patients who underwent kidney transplant (Ref: Cinacalcet)

\begin{tabular}{llll}
\hline & HR & $95 \%$ CI & $P$ value \\
\hline $\begin{array}{l}\text { Model 1 } \\
\begin{array}{l}\text { Parathyroidectomy } \\
\text { (Ref: Cinacalcet) }\end{array}\end{array}$ & 0.474 & $0.398,0.564$ & $<.0001$ \\
$\begin{array}{l}\text { Model 2 } \\
\text { Parathyroidectomy } \\
\text { (Ref: Cinacalcet) }\end{array}$ & 0.474 & $0.396,0.561$ & $<.0001$ \\
\hline
\end{tabular}

Model 1: PTH serum was excluded from the model

Model 2: PTH serum was adjusted for within the cox regression

In conclusion, this large database study, the first of its kind, shows that parathyroidectomy is associated with an overall better survival than Cinacalcet in patients with secondary hyperparathyroidism on hemodialysis. Surgery should be strongly considered particularly in patients with PTH levels higher than $1000 \mathrm{pg} / \mathrm{dL}$. While the conduct of a randomized prospective study comparing the two treatment modalities is feasible, it is certainly an enormous undertaking and unlikely to be performed soon. Because of this, the results of this analysis are an invaluable asset to help guide decision making for clinicians caring for these complex patients.

\section{Declarations}

Conflict of interests The authors declare that they have no conflict of interests.

Open Access This article is licensed under a Creative Commons Attribution 4.0 International License, which permits use, sharing, adaptation, distribution and reproduction in any medium or format, as long as you give appropriate credit to the original author(s) and the source, provide a link to the Creative Commons licence, and indicate if changes were made. The images or other third party material in this article are included in the article's Creative Commons licence, unless indicated otherwise in a credit line to the material. If material is not included in the article's Creative Commons licence and your intended use is not permitted by statutory regulation or exceeds the permitted use, you will need to obtain permission directly from the copyright holder. To view a copy of this licence, visit http://creativecommons. org/licenses/by/4.0/

\section{References}

1. Block GA, Klassen PS, Lazarus JM, Ofsthun N, Lowrie EG, Chertow GM (2004) Mineral metabolism, mortality, and morbidity in maintenance hemodialysis. J Am Soc Nephrol 15(8):2208-2218

2. Floege J, Kim J, Ireland E, Chazot C, Drueke T, de Francisco A et al (2011) Serum iPTH, calcium and phosphate, and the risk of mortality in a European haemodialysis population. Nephrol Dial Transplant 26(6):1948-1955
3. Kalantar-Zadeh K, Kuwae N, Regidor DL, Kovesdy CP, Kilpatrick RD, Shinaberger CS et al (2006) Survival predictability of time-varying indicators of bone disease in maintenance hemodialysis patients. Kidney Int 70(4):771-780

4. Kidney Disease: Improving Global Outcomes (KDIGO) CKDMBD Update Work Group (2017) KDIGO 2017 clinical practice guideline update for the diagnosis, evaluation, prevention, and treatment of chronic kidney disease-mineral and bone disorder (CKD-MBD). Kidney Int Suppl (2011) 7(1):1-59

5. Lindberg JS, Culleton B, Wong G, Borah MF, Clark RV, Shapiro WB et al (2005) Cinacalcet $\mathrm{HCl}$, an oral calcimimetic agent for the treatment of secondary hyperparathyroidism in hemodialysis and peritoneal dialysis: a randomized, double-blind, multicenter study. J Am Soc Nephrol 16(3):800-807

6. Block GA, Martin KJ, de Francisco AL, Turner SA, Avram MM, Suranyi MG et al (2004) Cinacalcet for secondary hyperparathyroidism in patients receiving hemodialysis. N Engl J Med 350(15):1516-1525

7. EVOLVE Trial Investigators, Chertow GM, Block GA, CorreaRotter R, Drueke TB, Floege J et al (2012) Effect of cinacalcet on cardiovascular disease in patients undergoing dialysis. N Engl J Med 367(26):2482-2494

8. Ishani A, Liu J, Wetmore JB, Lowe KA, Do T, Bradbury BD et al (2015) Clinical outcomes after parathyroidectomy in a nationwide cohort of patients on hemodialysis. Clin J Am Soc Nephrol 10(1):90-97

9. Cruzado JM, Moreno P, Torregrosa JV, Taco O, Mast R, GomezVaquero $C$ et al (2016) A randomized study comparing parathyroidectomy with cinacalcet for treating hypercalcemia in kidney allograft recipients with hyperparathyroidism. J Am Soc Nephrol 27(8):2487-2494

10. Foley RN, Li S, Liu J, Gilbertson DT, Chen SC, Collins AJ (2005) The fall and rise of parathyroidectomy in U.S. hemodialysis patients, 1992 to 2002. J Am Soc Nephrol 16(1):210-218

11. Kestenbaum B, Seliger SL, Gillen DL, Wasse H, Young B, Sherrard DJ et al (2004) Parathyroidectomy rates among United States dialysis patients: 1990-1999. Kidney Int 65(1):282-288

12. Gasparri G, Camandona M, Abbona GC, Papotti M, Jeantet A, Radice E et al (2001) Secondary and tertiary hyperparathyroidism: causes of recurrent disease after 446 parathyroidectomies. Ann Surg 233(1):65-69

13. Filho WA, van der Plas WY, Brescia MDG, Nascimento CP Jr, Goldenstein PT, Neto LMM et al (2018) Quality of life after surgery in secondary hyperparathyroidism, comparing subtotal parathyroidectomy with total parathyroidectomy with immediate parathyroid autograft: prospective randomized trial. Surgery 164(5):978-985

14. Callender GG, Malinowski J, Javid M, Zhang Y, Huang H, Quinn CE et al (2017) Parathyroidectomy prior to kidney transplant decreases graft failure. Surgery 161(1):44-50

15. Mathur A, Sutton W, Ahn JB, Prescott JD, Zeiger MA, Segev DL et al (2021) Association between treatment of secondary hyperparathyroidism and posttransplant outcomes. Transplantation 105:e366-e374

16. Kestenbaum B, Andress DL, Schwartz SM, Gillen DL, Seliger SL, Jadav PR et al (2004) Survival following parathyroidectomy among United States dialysis patients. Kidney Int 66(5):2010-2016

17. Kim SM, Long J, Montez-Rath ME, Leonard MB, Norton JA, Chertow GM (2016) Rates and outcomes of parathyroidectomy for secondary hyperparathyroidism in the United States. Clin J Am Soc Nephrol 11(7):1260-1267

18. Yusuf AA, Howell BL, Powers CA, St Peter WL (2014) Utilization and costs of medications associated with CKD mineral 
and bone disorder in dialysis patients enrolled in Medicare Part D. Am J Kidney Dis 64(5):770-780

19. Kim WW, Rhee Y, Kim BS, Kim K, Lee CR, Kang SW et al (2019) Clinical outcomes of parathyroidectomy versus cinacalcet in the clinical management of secondary hyperparathyroidism. Endocr J 66(10):881-889

20. Brandenburg VM, Floege J (2008) Adynamic bone disease-bone and beyond. NDT Plus 1(3):135-147
21. Heaf J (2001) Causes and consequences of adynamic bone disease. Nephron 88(2):97-106

Publisher's Note Springer Nature remains neutral with regard to jurisdictional claims in published maps and institutional affiliations. 